\title{
When Rankings Go Too Far
}

\author{
PHIL BATY
}

Phil Baty is editor of the Times Higher Education's World University Rankings. http://bit.ly/thewurTimes Higher Education. An earlier version of this article appears in University World News and is published here with permission. E-mail: Phil.Baty@tsleducation.com.

When governments seek to identify the world's best universities, they increasingly rely on global university rankings. In Russia, Prime Minister Dmitry Medvedev recently signed an order awarding official recognition to degrees from 210 leading universities from 25 countries-determined in large part by their presence in the Times Higher Education's World University Rankings. The thousands set to benefit from study-abroad scholarships under Russia's fivebillion ruble (US\$152 million) the Global Education program will also have to attend a top-ranked university.

A similar scholarship project in Brazil, the $£ 1.3$ billion (US\$2 billion) Science without Borders program for 100,000 students, also draws heavily on the Times Higher Education and other rankings to select the host institutions. And in India this month, the government's Universities Grants Commission set out new rules to ensure that only 500 universities ranked by Times Higher Education or the Shanghai Academic Ranking of World Universities are allowed to run joint- 
degree or twinning courses with Indian partners. Such high-level official endorsement of Times Higher Education's work is, of course, gratifying.

\section{TIMES HIGHER EDUCATION'S APPROACH}

This magazine has published a global university ranking since 2004, but as the reach and influence of our work grew, we needed to work harder to produce research that could better bare the increasing weight that was being placed upon it. So in 2009, after a thorough review of our rankings work, we scrapped the system used for the previous five years and started again. We ripped up the overly simplistic model that had been hampering global rankings for years and changed the game.

First, we brought in a new expert data partner, Thomson Reuters. In concert with Thomson Reuters, with input from more than 50 leading figures from 15 countries across every continent, and after 10 months of open debate and consultation-we developed a new rankings system for a new era of globalized higher education. Fortunately, the review produced the most balanced and comprehensive rankings system around.

Times Higher Education's global rankings are the only ones in the world to examine all core missions of the modern global research university-research, teaching, knowledge transfer, and international activity. They are the only rankings to fully reflect the unique subject mix of each and every institution across the full range of performance indicators and to take a proper account of excellence in the arts, humanities, and social sciences—so badly neglected by other rankings. They are the only global rankings to employ a rigorous, 
invitation-only survey of experienced, expert academics-with no volunteers and certainly no nominations from universities themselves.

Indeed, our work has attracted glowing praise from many quarters. I was particularly satisfied to read the words of a rankings skeptic-Daniel Lincoln, visiting scholar at the Center for International Higher Education at Boston College-who recently noted that "Baty and THE are well known for their integrity as well as their sincerity."

\section{CAveats}

But a reputation for integrity must be earned and maintained through open and honest discussions about both the uses and the abuses of global rankings. All global university ranking tables are inherently crude, as they reduce universities and all their diverse missions and strengths to a single, composite score. Anyone who adheres too rigidly to rankings tables risks missing the many pockets of excellence in narrower subject areas not captured by institution-wide rankings or in areas of university performance that are simply not captured well by any ranking.

For example, all of the global rankings put the most emphasis on research evaluation, judged primarily through the examination of citations to research papers published in the leading international journals. This may not best serve the interests of emerging research institutions in developing nations, where research publication may be more of a national or regional activity, and it certainly does not serve those whose mission is focused on teaching.

One of the great strengths of global higher education is its extraordinarily rich diversity; and this can never be captured by any global ranking, which 
judges all institutions against a single set of criteria. In this context, a new declaration from a consortium of Latin American university rectors must be welcomed.

The declaration, agreed at a two-day conference at the National Autonomous University of Mexico, titled "Latin American Universities and the International Rankings: Impact, Scope and Limits," noted with concern that "a large proportion of decision makers and the public view these classification systems as offering an exhaustive and objective measure of the quality of the institutions." No university ranking can ever be exhaustive or objective. The meeting, which drew together rectors and senior officials from 65 universities in 14 Latin American countries, issued a call to policymakers to "avoid using the results of the rankings as elements in evaluating the institution's performance, in designing higher education policy, in determining the amount of finance for institutions and in implementing incentives and rewards for institutions and academic personnel."

Responsibly and transparently compiled rankings can, of course, have a very useful role in allowing institutions to benchmark their performance and to help them plan their strategic direction. They can inform student choices and help faculty make career decisions. They can help governments to better understand some of the modern policy challenges of mass higher education in the knowledge economy and to compare the performance of their best researchled institutions to those of rival nations. And yes, they can play a role in helping governments to select potential partners for their home institutions and determine where to invest their scholarships. 
But they can only play a helpful role if those of us who rank are honest about what rankings do not—and can never-capture, as much as what they can, and as long as we encourage users to dig deeper than the composite scores that can mask real excellence in specific fields or areas of performance. Times Higher Education is working hard to expand the range of data that it releases and to allow more disaggregation of the ranking results and more nuanced analyses. Rankings can be a valuable tool for global higher educationbut only if handled with care. 